\title{
Catalyst Residue and Oxygen Species Inhibition of the Formation of Hexahapto-Metal Complexes of Group 6 Metals on Single-Walled Carbon Nanotubes
}

\author{
Kourtney D. Wright ${ }^{1}$ and Andrew R. Barron ${ }^{1,2,3, *}$ \\ 1 Department of Chemistry, Rice University, Houston, TX 77005, USA; kourtney.wright@yahoo.com \\ 2 Department of Materials Science and Nanoengineering, Rice University, Houston, TX 77005, USA \\ 3 Energy Safety Research Institute, Swansea University Bay Campus, Swansea SA2 8QQ, UK \\ * Correspondence: arb@rice.edu or a.r.barron@swansea.ac.uk; Tel.: +1-713-348-5610 \\ Academic Editor: Alvin Orbaek White \\ Received: 16 April 2017; Accepted: 16 May 2017; Published: 26 May 2017
}

\begin{abstract}
The reaction of Group 6 metals with SWCNT has the potential to bridge the resistive SWCNT $\cdots$ SWCNT junctions by the formation of " $\mathrm{Cr}(\mathrm{SWCNT})_{2}$ " complexes analogous to $\mathrm{Cr}\left(\mathrm{C}_{6} \mathrm{H}_{6}\right)_{2}$. This study reports that the formation of such species is very sensitive to oxidation by a residual iron oxide catalyst used for the growth of the SWCNTs and adsorbed/bound oxygen functionality. The reaction of raw HiPco SWCNTs with $\mathrm{M}(\mathrm{CO})_{6}$ and $\left(\mathrm{C}_{7} \mathrm{H}_{8}\right) \mathrm{M}(\mathrm{CO})_{3}(\mathrm{M}=\mathrm{Cr}, \mathrm{W})$ or $\left(\mathrm{C}_{6} \mathrm{H}_{6}\right) \mathrm{Cr}(\mathrm{CO})_{3}$ results in the formation of the Group 6 metal oxides. Annealing and acid treating the HiPco SWCNTs to reduce the catalyst content allows for the observation of zero valent metals by XPS, while the use of very high purity SWCNTs and graphene allows for the addition of primarily zero valent Group 6 metals, including the bis-hexahapto metal complex.
\end{abstract}

Keywords: chromium; tungsten; carbon nanotube; graphene; XPS

\section{Introduction}

The isolobal relationship between arenes and nano carbon materials suggests that the coordination of metals to their surface should be facile [1]. In particular, $\eta^{6}$-coordination of the Group 6 metals (Cr, Mo, and W) should be possible. Whereas the curvature of fullerenes disfavors $\eta^{5}$ - or $\eta^{6}$-coordination due to the $\pi$-orbitals being directed away from the metal center, this is less of an issue in carbon nanotubes (CNTs) due to their lower circular (rather than spherical) strain [2]. More importantly, the orbital overlap offers the potential for the alteration of the electronic properties of CNT bundles, without breaking the $\mathrm{sp}^{2}$ hybridization of the tubes [3]. Further, theoretical calculations have shown that there is no potential barrier between semiconducting single walled carbon nanotubes (SWCNTs) and a molybdenum contact, indicating that electrons flow freely between the two [4]. Thus, the formation of Group 6 metal-SWCNT sandwich complexes has the potential to act as an electronic bridge between the resistive metallic and semiconducting SWCNT junctions present in bundles of tubes [5]. The formation mechanism of $\mathrm{Cr}(\mathrm{SWNT})_{2}$ should be analogous to that of related organometallic chromium systems [6].

In a study by Haddon and co-workers, it was reported that $\mathrm{Cr}(0)$ is effective in increasing the conductivity of SWCNTs by the formation of $\mathrm{Cr}(\mathrm{SWCNT})_{2}$ complexes that reduce the inter-nanotube junction resistance [7]. In concept, this is an extension of doping studies where metal and non-metal species are known to intercalate within CNT bundles [5]. As part of their work, it was reported that the " $\mathrm{Cr}(\mathrm{CO})_{3}$ " moiety could be coordinated to both the graphene surface and also the sidewalls of SWCNTs [5,7]. Films of their $\mathrm{Cr}(\mathrm{SCWNT})_{2}$ sandwich complex were observed to have an increase in 
conductivity of over 100\% [5]. They also reported conductivity increases for tungsten and molybdenum sandwich complexes synthesized by the same method [7].

During our study of the interaction of metals with SWCNTs, as part of our interest in the enhanced conductivity of metal-SWCNTs composites [8,9], we wanted to explore the use of these " $\mathrm{Cr}(\mathrm{CO})_{3}$ " complexes as seeds for the growth of metal particles with intimate electronic interaction to the side-wall (as opposed to the end) of the SWCNTs. However, our initial experimentation did not result in the formation of the claimed "(SWCNT)Cr(CO $)_{3}$ " species. In particular, the lack of a $\mathrm{Cr}(0)$ peak in the XPS analysis and consistent IR spectra provided no evidence for the formation of the claimed species.

The Haddon Group reported a $\mathrm{Cr} 2 \mathrm{p}_{3 / 2}$ binding energy for (SWCNT) $\mathrm{Cr}(\mathrm{CO})_{3}$ of $576.9 \mathrm{eV}$ as being consistent with $\mathrm{Cr}(0) \eta^{6}$-complexes [7]; however, the accepted value for $\left(\mathrm{C}_{6} \mathrm{H}_{6}\right) \mathrm{Cr}(\mathrm{CO})_{3}$ is $576.1 \mathrm{eV}$ [10]. We note that they also reported the binding energy for $\mathrm{Cr}_{2} \mathrm{O}_{3}$ to be $575.5 \mathrm{eV}$, which does not fall within the accepted literature values of 575.7-578.9 eV [11]. Additionally, the infrared spectrum of the species assigned to (SWCNT) $\mathrm{Cr}(\mathrm{CO})_{3}$ is reported to show a single signal for the carbonyls at $1971 \mathrm{~cm}^{-1}$ [7], but the local environment of " $(\mathrm{SWCNT}) \mathrm{Cr}(\mathrm{CO})_{3}$ " has a $\mathrm{C}_{3 \mathrm{v}}$ symmetry [12]. With this symmetry, the $\mathrm{A}_{1}$ and $\mathrm{E}$ vibration modes are IR-active; therefore, two bands should be observed, as seen in the spectra of $\left(\mathrm{C}_{6} \mathrm{H}_{6}\right) \mathrm{Cr}(\mathrm{CO})_{3}$ [12]. The observation of a single peak is more in line with the presence of unreacted $\mathrm{Cr}(\mathrm{CO})_{6}$ starting material, which shows a single signal at $2000 \mathrm{~cm}^{-1}$ [7]. The observation of a shift to lower wavenumbers is consistent with physisorption $[13,14]$. Thus, the characterization reported was inconsistent with the proposed species.

It is conventional to view SWCNTs as molecular species that are extensions of the lower fullerenes $\left(\mathrm{C}_{60}, \mathrm{C}_{70}\right.$, etc.); however, while they are idealized in graphical representations as pristine carbon species, this is far from the truth. In reality, SWCNTs comprise a myriad of species that are dependent on the route of their synthesis and the method of purification. Open termini contain oxygen functional groups such as hydroxides and carboxylic acids [15], while side-walls have significant concentrations of epoxides [16]. The concentration of the latter functional group can be one oxygen per 123 carbon atoms in as prepared samples and as high as one oxygen per 105 carbon atoms in "purified" samples [16]. Clearly, this dramatically alters the chemical nature of the surface of the SWCNT, although this is often used as an advantage when reacting species at the surface $[17,18]$. Another complication in the real picture of SWCNTs is the presence of significant residue from the catalyst used to grow the tubes. In most cases, this exists as metal and metal oxide particles, and is often iron-based, such as found in HiPco SWCNTs [19]. The presence of the metal has raised concerns with regard to bio-nano interactions, where oxidative stress and a decrease in cell viability are consequences of the large proportion of metal catalyst (iron and nickel) [20,21]. Although the study of nanotubes in biological systems is very different from the organometallic system under investigation here, it illustrates the significance of the residual catalyst materials and exemplifies the need for further investigation into their effects on chemical systems.

\section{Results and Discussion}

\subsection{Reaction of Group 6 Complexes with Raw SWCNTs}

HiPco SWCNTs were reacted with $\mathrm{Cr}(\mathrm{CO})_{6},\left(\mathrm{C}_{7} \mathrm{H}_{8}\right) \mathrm{Cr}(\mathrm{CO})_{3}$, and $\left(\mathrm{C}_{6} \mathrm{H}_{6}\right) \mathrm{Cr}(\mathrm{CO})_{3}$, with the goal being to maximize the amount of zero-valent Group 6 metals deposited on the SWCNTs. XPS analysis of the resulting products confirmed the presence of $\mathrm{Cr}$ (Table 1). The $\mathrm{Cr}$ content follows the trend: $\left(\mathrm{C}_{7} \mathrm{H}_{8}\right) \mathrm{Cr}(\mathrm{CO})_{3}>\mathrm{Cr}(\mathrm{CO})_{6}>\left(\mathrm{C}_{6} \mathrm{H}_{6}\right) \mathrm{Cr}(\mathrm{CO})_{3}$.

Without curve fitting, the high resolution $\mathrm{Cr} 2 \mathrm{p}_{3 / 2}$ spectra for the products with $\mathrm{Cr}(\mathrm{CO})_{6}$, $\left(\mathrm{C}_{6} \mathrm{H}_{6}\right) \mathrm{Cr}(\mathrm{CO})_{3}$, and $\left(\mathrm{C}_{7} \mathrm{H}_{8}\right) \mathrm{Cr}(\mathrm{CO})_{3}$ are centered at 577.0, 577.3, and $576.7 \mathrm{eV}$, respectively, which is similar to that reported by Kalinina et al. (576.9 eV) [7]. However, comparing the deconvoluted spectra (Figure 1a, Table 1) with the literature values for various $\mathrm{Cr}$ species (Table 2), it appears that these peaks are more likely associated with $\mathrm{Cr}$ oxides, since the literature reports that the $\mathrm{Cr} 2 \mathrm{p}_{3 / 2}$ peaks for $\left(\mathrm{C}_{6} \mathrm{H}_{6}\right) \mathrm{Cr}(\mathrm{CO})_{3}$ and $\left(\mathrm{C}_{6} \mathrm{H}_{6}\right) \mathrm{Cr}\left(\mathrm{C}_{6} \mathrm{H}_{6}\right)$ occur at 576.1 and $575.2 \mathrm{eV}$, respectively [10]. Thus, the reported 


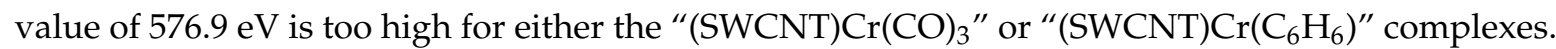
In addition, the literature also reports a multi-peak structure for the $\mathrm{Cr} 2 \mathrm{p}$ spectra of $\mathrm{Cr}(\mathrm{CO})_{6}$ and $\left(\mathrm{C}_{6} \mathrm{H}_{6}\right) \mathrm{Cr}(\mathrm{CO})_{3}$ from shake-up-shake-off processes [10]. Neither our spectra, nor those previously assigned to (SWCNT) $\mathrm{Cr}(\mathrm{CO})_{3}$, display these shake up peaks, despite having the same local structure as $\left(\mathrm{C}_{6} \mathrm{H}_{6}\right) \mathrm{Cr}(\mathrm{CO})_{3}$ [7].

Table 1. Observed XPS Cr 2 $\mathrm{p}_{3 / 2}$ binding energies and atomic percentages for reactions of SWCNTs.

\begin{tabular}{cccc}
\hline Reagent & Cr Content (\%) & Cr 2p3/2 Binding Energy (eV) & FWHM (eV) \\
\hline$\left(\mathrm{C}_{6} \mathrm{H}_{6}\right) \mathrm{Cr}(\mathrm{CO})_{3}$ & \multirow{2}{*}{1.70} & 576.2 & 1.45 \\
& & 577.4 & 1.75 \\
& \multirow{3}{*}{3.5} & 578.9 & 1.75 \\
& & 576.0 & 1.45 \\
& & 577.3 & 1.75 \\
$\left(\mathrm{C}_{7} \mathrm{H}_{8}\right) \mathrm{Cr}(\mathrm{CO})_{6}$ & \multirow{2}{*}{5.01} & 578.9 & 1.75 \\
& & 576.1 & 1.45 \\
& & 577.3 & 1.75 \\
& & 578.9 & 1.75 \\
\hline
\end{tabular}

Table 2. Literature values of the XPS Cr $2 \mathrm{p}_{3 / 2}$ binding energies for various chromium species.

\begin{tabular}{ccc}
\hline Species & Binding Energy (eV) & Reference \\
\hline $\mathrm{Cr}$ metal & 574.2 & 11 \\
$\mathrm{Cr}\left(\mathrm{C}_{6} \mathrm{H}_{6}\right)_{2}$ & 575.2 & 10 \\
$\left(\mathrm{C}_{6} \mathrm{H}_{6}\right) \mathrm{Cr}(\mathrm{CO})_{3}$ & 576.1 & 10 \\
$\mathrm{Cr}(\mathrm{CO})_{6}$ & 576.8 & 10 \\
$\mathrm{Cr}_{2} \mathrm{O}_{3}{ }^{a}$ & $575.7-578.9$ & 22 \\
$\mathrm{CrO}_{3}$ & 579.6 & 22 \\
\hline
\end{tabular}

a The binding energy of the most intense portion of the peak without curve fitting is 576.8 .

Kalinina et al. report that the binding energy of the $\mathrm{Cr} 2 \mathrm{p}_{3 / 2}$ and $2 \mathrm{p}_{1 / 2}$ signals for "(SWCNT) $\mathrm{Cr}(\mathrm{CO})_{3}$ " were 576.9 and $586.5 \mathrm{eV}$, respectively, without curve fitting [7]. This corresponds to a spin-orbit splitting of $9.7 \mathrm{eV}$. However, spin-orbit splitting for zero valent $\mathrm{Cr}$ compounds is generally between 8.7 and $9.2 \mathrm{eV}$ [22]. In this regard, the values for $\mathrm{Cr}(\mathrm{CO})_{6},\left(\mathrm{C}_{6} \mathrm{H}_{6}\right) \mathrm{Cr}(\mathrm{CO})_{3}$, and $\left(\mathrm{C}_{6} \mathrm{H}_{6}\right) \mathrm{Cr}\left(\mathrm{C}_{6} \mathrm{H}_{6}\right)$ are 8.9, 8.8, and $9.1 \mathrm{eV}$, respectively [10]. In contrast, the value for $\mathrm{Cr}_{2} \mathrm{O}_{3}$ is $9.7 \mathrm{eV}$ [22]. Clearly, the spin-orbit splitting observed in both our study and that previously [7] is consistent with an oxide rather than a zero valent species. The full width half $\max \left(\mathrm{FWHM}\right.$ ) for our spectra $\mathrm{Cr} 2 \mathrm{p}_{3 / 2}$ signal (without curve fitting) is $2.6-2.9 \mathrm{eV}$, which is similar to that reported by Kalinina et al. (2.3-2.7 eV) [7]. While these values are smaller than that observed for $\mathrm{Cr}_{2} \mathrm{O}_{3}(3.0 \mathrm{eV})$ without taking into consideration multiplet splitting [22], they are significantly larger than those reported for bona fide zero valent chromium compounds (1.7 and $2.3 \mathrm{eV}$ ) [10]. Based upon the forgoing, it appears that while our spectra are in agreement with those reported previously [7], these peaks are actually indicative of $\mathrm{Cr}_{2} \mathrm{O}_{3}$, suggesting that either oxidation of the $\mathrm{Cr}$ has occurred during the reaction or upon exposure to air post-reaction.

The deconvoluted $\mathrm{Cr} 2 \mathrm{p}_{3 / 2}$ XPS spectra show a peak around $576.1 \mathrm{eV}$ for the products from all three $\mathrm{Cr}$ starting materials (Table 1). The shift is identical to that reported for $\left(\mathrm{C}_{6} \mathrm{H}_{6}\right) \mathrm{Cr}(\mathrm{CO})_{3}$, and the FWHM of this peak is $1.45 \mathrm{eV}$, which is nearer the range reported for zero-valent chromium (1.8 to $2.3 \mathrm{eV}$ ) [22]. This suggests that these products may indeed contain (SWCNT) $\mathrm{Cr}(\mathrm{CO})_{3}$ as a minor component alongside $\mathrm{Cr}_{2} \mathrm{O}_{3}$. However, it should be noted that this peak is also within the range reported for $\mathrm{Cr}$ (III) species and that $\mathrm{Cr}$ (III) has multiplet splitting in XPS, which makes curve fitting used to determine oxidation states very challenging [11]. Indeed, it has been calculated that 65 multiplet peaks exist in XPS $2 p$ spectra of $\mathrm{Cr}$ (III) species [23]. However, experimentally, these multiplets appear as 'bundles' of peaks (typically five for the $2 \mathrm{p}_{3 / 2}$ peak), which must be fit with varying FWHM values and peak heights to allow for electron coupling, as well as variances in the lifetime broadening [24]. 

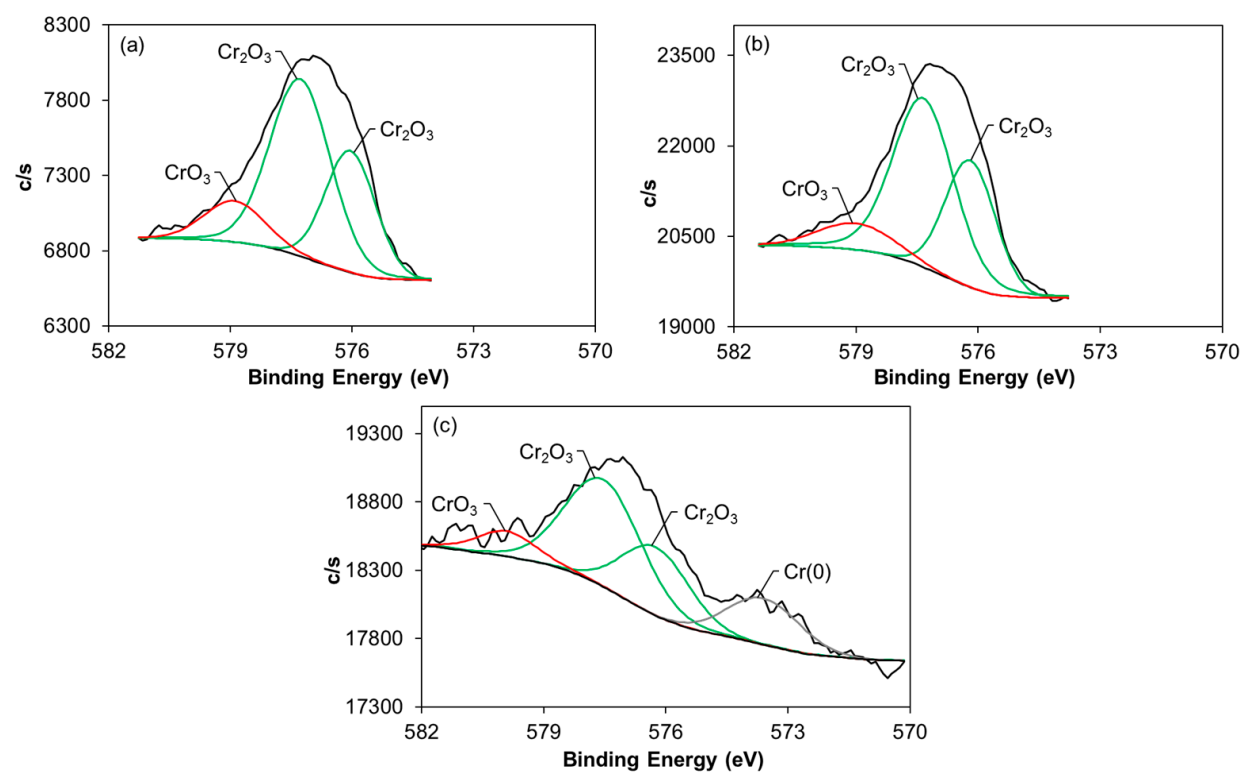

Figure 1. The $\mathrm{Cr} 2 \mathrm{p}_{3 / 2}$ XPS signal for the product of the reaction between $\mathrm{Cr}(\mathrm{CO})_{6}$ and (a) raw HiPco SWCNTs, (b) iron oxide powder, and (c) SWCNTs after microwave/ $\mathrm{HCl} /$ anneal treatment. $\mathrm{Cr}_{2} \mathrm{O}_{3}$ is fit with two curves to account for its complex multiplet splitting [23].
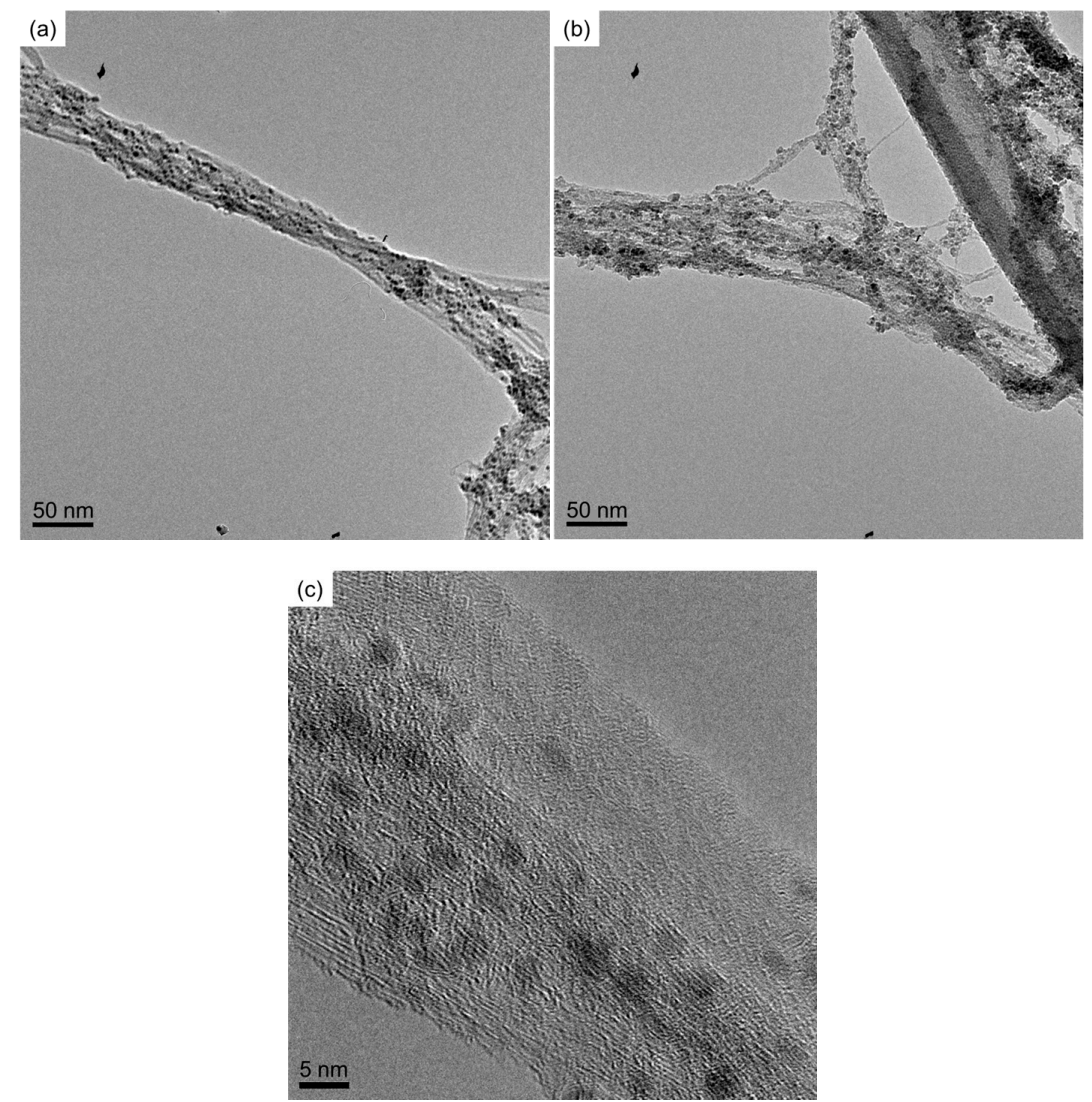

Figure 2. TEM image of (a) raw HiPco SWCNTs and $(\mathbf{b}, \mathbf{c})$ the product from the reaction of $\left(\mathrm{C}_{6} \mathrm{H}_{6}\right) \mathrm{Cr}(\mathrm{CO})_{3}$ with raw HiPco SWCNTs.

In the prior work [7], SEM images of increased bundle size were suggested as being an indicator of interconnects, i.e., $\mathrm{Cr}(\mathrm{SWCNT})_{2}$. However, the TEM images showed surface particles of a ca. $1 \mathrm{~nm}$ diameter, which would be consistent with a small cluster based upon the diameter of $\mathrm{Cr}(0.424 \mathrm{~nm})$ [25]. 
TEM images of our samples show similar particulates, but these are impossible to differentiate from the residual catalyst materials on raw HiPco SWCNTs (Figure 2).

The presence of oxidized products could be put down to the reaction with adventitious oxygen; however, since careful air-free techniques (including the use of degassed THF distilled over sodium/benzophenone) were used in the reactions, it is also possible that the Group 6 metal oxidation occurred with the oxygen impurities that are present on the outside of the SWCNTs [26]. To prevent this, the oxygen was removed from the SWCNTs by annealing them at $550{ }^{\circ} \mathrm{C}$ in an inert atmosphere [19]; however, this did not solve the oxidation problem. As noted in the introduction, we have been concerned with issues associated with the presence of residual catalyst particles in SWCNTs with regard to any meaningful investigation of their reactivity. Based upon prior work, we suggested that the presence of oxidized $\mathrm{Cr}$ species is due to a reaction with the iron oxide catalyst residue that is commonly present $[21,22,27]$.

\subsection{Reaction of $\mathrm{Cr}(\mathrm{CO})_{6}$ with Iron Oxide}

A consideration of the standard reduction potentials shows that iron oxides, in particular $\mathrm{Fe}(\mathrm{III})$, could be causing the oxidation of zero valent chromium [28]. To confirm the impact of the catalyst residue, $\mathrm{Cr}(\mathrm{CO})_{6}$ was heated in freshly distilled THF in the presence of mixed iron(II,III) oxide powder. After filtration, the sample was washed to remove any residual $\mathrm{Cr}(\mathrm{CO})_{6}$, and the resulting red powder was analyzed by XPS. In addition to the expected iron species, the powder contained $\mathrm{Cr}(11.37 \%)$, indicating that the reaction had indeed occurred.

The high resolution Fe $2 \mathrm{p}_{3 / 2}$ signals (Figure 3) show the presence of $\mathrm{Fe}(\mathrm{III})$ and $\mathrm{Fe}(\mathrm{II})$ in both the starting material and the product; however, there is a distinct shift in the relative speciation. Analyzing the peak areas shows an increase in $\mathrm{Fe}(\mathrm{II})$ from 58 to $63 \%$ after heating with $\mathrm{Cr}(\mathrm{CO})_{6}$. As expected, the $\mathrm{Cr} 2 \mathrm{p}_{3 / 2}$ signal (Figure $1 \mathrm{~b}$ ) shows no zero valent chromium in the sample, and assuming that the unreacted $\mathrm{Cr}(\mathrm{CO})_{6}$ was removed by washing (and through sublimation in the UHV of the XPS chamber), the peak is consistent with a mixture of $\mathrm{Cr}_{2} \mathrm{O}_{3}$ and $\mathrm{CrO}_{3}$ [11]. The increase in $\mathrm{Fe}(\mathrm{II})$ content indicates that this observed oxidation is not due to accidental contamination with air or water, but rather that iron oxides do oxidize $\mathrm{Cr}(\mathrm{CO})_{6}$. Given that TGA analysis indicates, even within a single batch, that raw HiPco SWCNTs contain 20-40 w/w \% oxidized iron catalyst, the removal of this residue is imperative if zero valent Group 6 moieties are to be formed on SWCNTs.
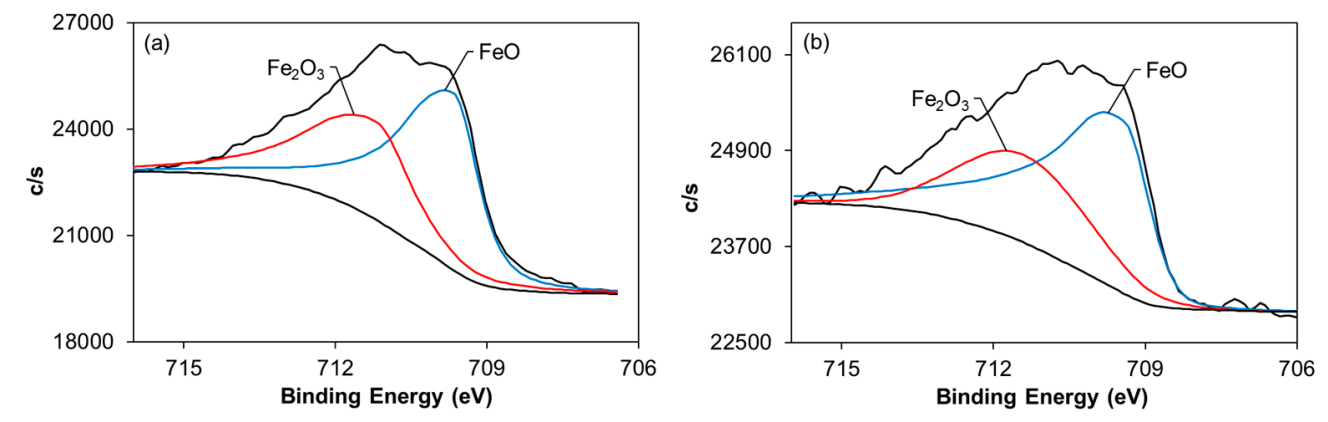

Figure 3. The $\mathrm{Fe} 2 \mathrm{p}_{3 / 2} \mathrm{XPS}$ signals for (a) mixed iron oxide powder and (b) the product of the reaction with $\mathrm{Cr}(\mathrm{CO})_{6}$.

\subsection{XPS Analysis of SWCNT Purification}

The XPS analysis of raw HiPco SWCNTs and after thermal annealing under Ar and vacuum is shown in Table 3. The analysis of the high resolution O 1s XPS signal of the as received tubes (Figure 4) shows that the oxygen containing species comprise iron oxides $(530.3 \mathrm{eV})$, in addition to a range of oxygen moieties associated with the side walls of the SWCNTs. Prior studies suggest that the latter are due to the single and double bonds that oxygen makes to carbon in carboxylic acid, ketone, epoxide, 
and alcohol groups [16,29]. Annealing the tubes in argon or under vacuum reduces these oxygen moieties relative to the iron oxide peak (Table 3). Interestingly, annealing under argon appears to favor reduction in the $\mathrm{C}-\mathrm{O}$ species (Figure $4 \mathrm{~b}$ ), while annealing under vacuum (Figure $4 \mathrm{c}$ ) results in the reduction of both classes of substituent.
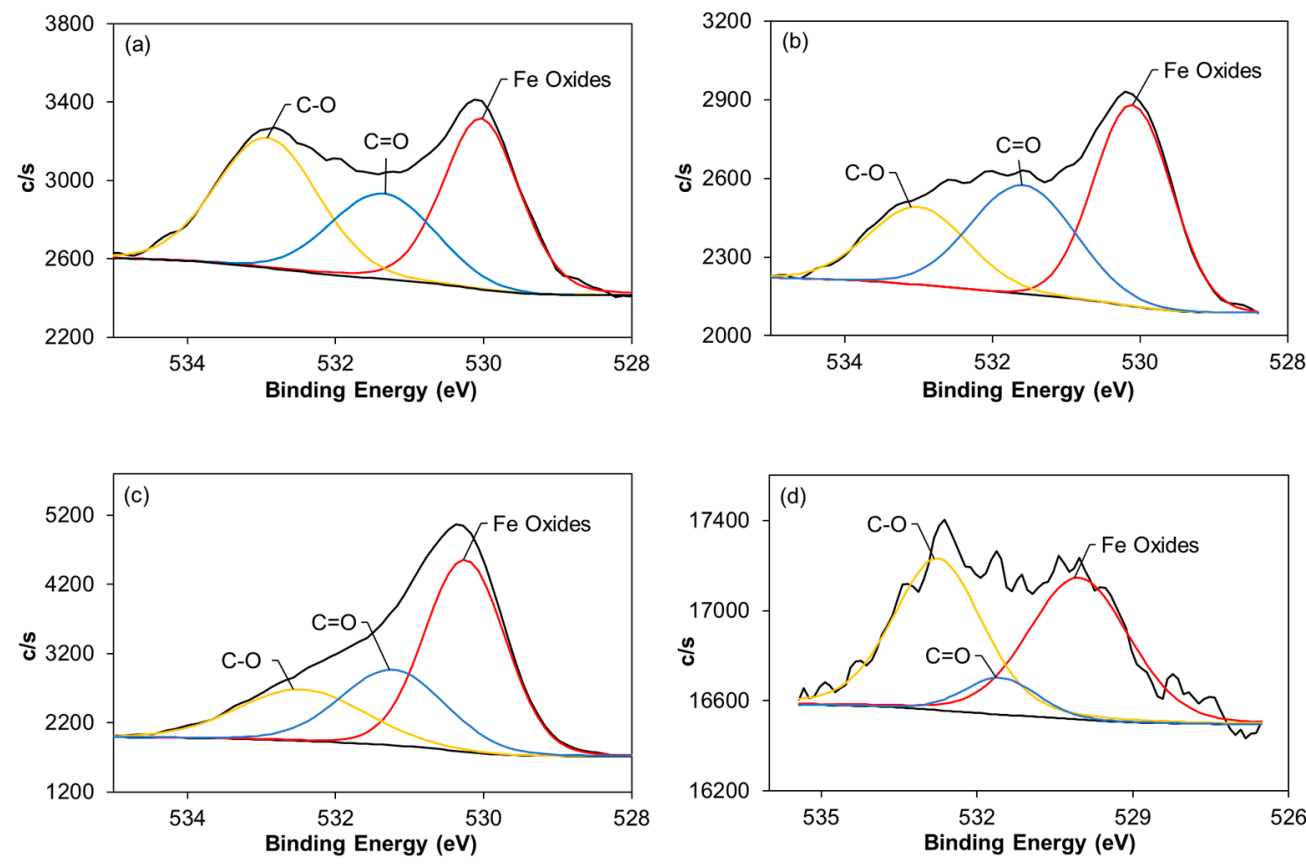

Figure 4. The high resolution XPS O 1s signals for (a) as received raw HiPco SWNTs, after annealing at $550{ }^{\circ} \mathrm{C}$ under (b) argon atmosphere and (c) dynamic vacuum, and (d) after combined microwaved $/ \mathrm{HCl} / \mathrm{Ar}$ anneal [27].

Table 3. XPS O 1s and Fe 2p assignment and relative composition for raw SWCNTs, after thermal annealing at $550{ }^{\circ} \mathrm{C}$ in argon or vacuum, and microwave treatment.

\begin{tabular}{cccccc}
\hline $\begin{array}{c}\text { Peak } \\
(\mathbf{e V})\end{array}$ & Assignment & $\begin{array}{c}\text { Raw-HiPco } \\
\mathbf{( \% )}\end{array}$ & $\begin{array}{c}\text { Ar Annealed } \\
\mathbf{( \% )}\end{array}$ & $\begin{array}{c}\text { Vacuum } \\
\text { Annealed (\%) }\end{array}$ & $\begin{array}{c}\text { Microwave/HCl/Ar } \\
\text { Annealed (\%) }\end{array}$ \\
\hline 533.3 & C-O & 37.47 & 22.68 & 21.74 & 45.40 \\
531.5 & C=O & 24.16 & 32.42 & 26.64 & 8.42 \\
530.0 & Fe oxides & 38.37 & 44.90 & 51.62 & 46.18 \\
706.6 & Fe(0) & 64.86 & 64.08 & 9.17 & 51.59 \\
709.5 & Fe(II) & 11.76 & 13.63 & 43.11 & 28.92 \\
711.0 & Fe(III) & 23.38 & 22.29 & 47.73 & 19.49 \\
\hline
\end{tabular}

An analysis of the Fe $2 \mathrm{p}_{3 / 2}$ signals (Figure 5 and Table 3) shows that the majority (ca. $65 \%$ ) of the Fe present in the raw SWCNT sample is due to zero valent iron, indicated by the peak at $706.6 \mathrm{eV}$ (Figure 5a); the remainder is a mixture of Fe(II) and Fe(III) oxides [11,30]. Annealing at $550{ }^{\circ} \mathrm{C}$ under Ar atmosphere has no obvious effect on the relative iron oxide concentration (Figure 5b). By contrast, annealing under vacuum increased the iron oxides relative to $\mathrm{Fe}(0)$ (Figure $5 \mathrm{c}$ ), presumably due to leaks in the system. In order to be able to successfully characterize zero valent species on SWCNTs, it is important to remove as much of the iron catalyst residue as possible, or alternatively, the higher oxidation states.

The most common routes for the removal of catalyst residue involve oxidation with $\mathrm{HNO}_{3}$, piranha, $\mathrm{H}_{2} \mathrm{SO}_{4}$, and others [31]. However, these treatments add oxygen functional groups [16,32], which are possibly detrimental to the chemistry of interest. We have previously reported that microwaving SWCNTs in air causes carbon-encapsulated iron to break out of its carbon shell and be oxidized, facilitating its chemical removal with acid or chlorine [27]. In an adaptation of the prior 
procedure, raw HiPco SWCNTs were subjected to microwave irradiation followed by refluxing in concentrated hydrochloric acid to dissolve the iron oxides, and finally annealing to $550{ }^{\circ} \mathrm{C}$ to remove oxygen functional groups, adsorbed oxygen, and any remaining acid residue. The XPS analysis of the resulting "cleaned" SWCNTs shows a decrease in the number of C=O groups on the SWCNTs (Figure 4d), as well as an overall decrease in oxygen species, as indicated by the lower signal intensity. In addition, a significant decrease in Fe(III) is observed relative to untreated SWCNTs (Figure 5d), which, given the reduction potentials, is most likely responsible for the oxidation of $\mathrm{Cr}(0)$.
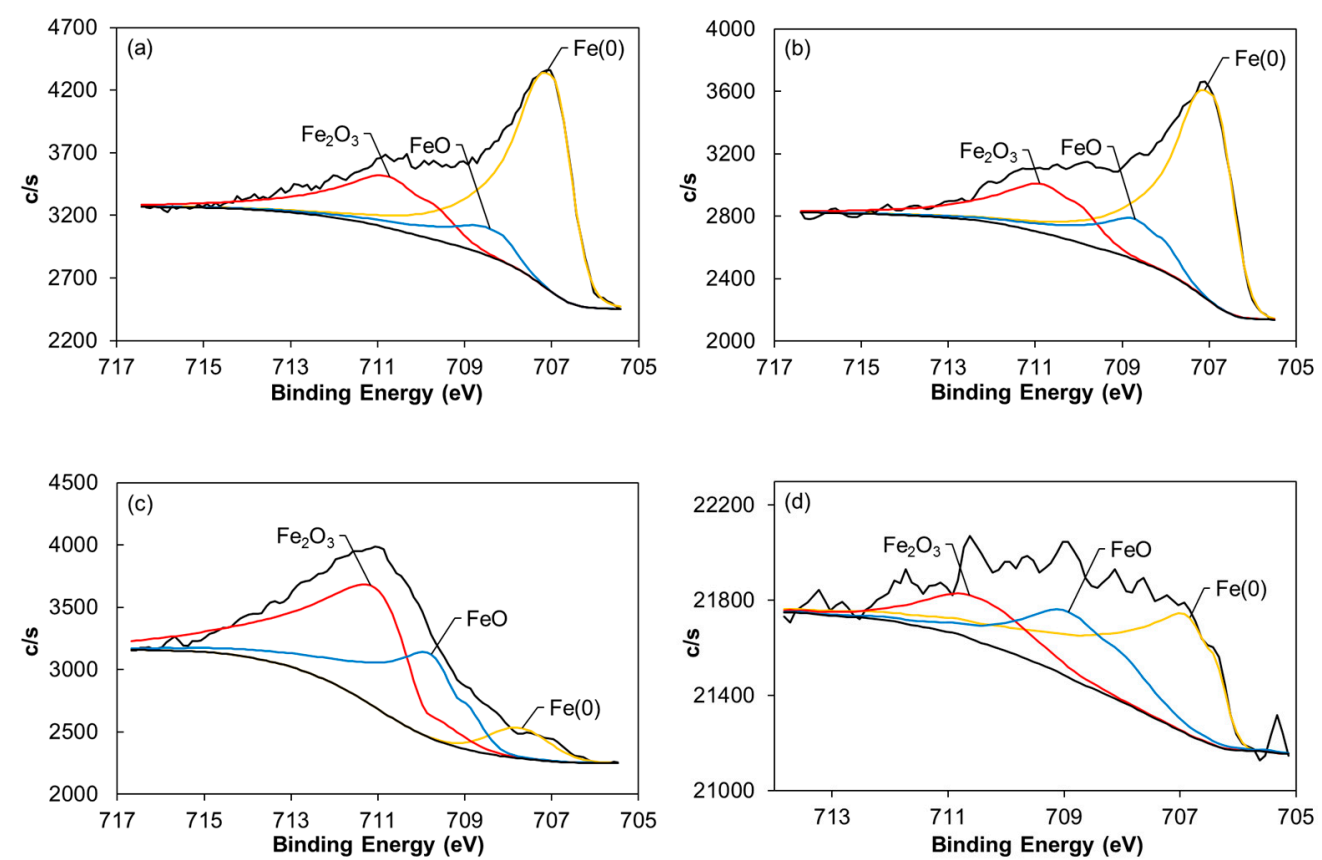

Figure 5. The Fe 2p XPS signals for (a) as received raw HiPco SWNTs, after annealing at $550{ }^{\circ} \mathrm{C}$ under (b) argon atmosphere and (c) dynamic vacuum, and (d) after combined microwaved/HCl/Ar anneal. For simplicity, the Fe(III) signal and its complex satellites are fitted with a single peak.

\subsection{Reaction of $\mathrm{Cr}(\mathrm{CO})_{6}$ with Purified SWCNTs}

Despite the incomplete removal of catalyst materials from the cleaned SWCNTs, the microwave $/ \mathrm{HCl} /$ annealed SWCNTs were chosen for further study due to the lowest Fe and in particular $\mathrm{Fe}(\mathrm{III})$ content. XPS was used to characterize the reaction product with $\mathrm{Cr}(\mathrm{CO})_{6}$. Figure $1 \mathrm{c}$ shows the $\mathrm{Cr} 2 \mathrm{p}_{3 / 2}$ peak, which indicates the presence of chromium oxides in a similar manner to that observed with the reaction with raw SWCNTs. Considering the incomplete removal of the iron catalyst from the SWCNTs, this is expected. However, unlike prior results, the chromium signal also has an $18.5 \%$ contribution from a zero valent chromium peak at $574.0 \mathrm{eV}$. It is important to note that this peak is in line with that expected for Cr metal [11]. However, as was previously discussed, the binding energy of $\left(\mathrm{C}_{6} \mathrm{H}_{6}\right) \mathrm{Cr}(\mathrm{CO})_{3}$ overlaps with that of chromium(III) oxide. There is a possibility that (SWCNT) $\mathrm{Cr}(\mathrm{CO})_{3}$ is also present in this sample, but it is very difficult to confirm. Additionally, the iron signal in Figure 6 shows a shift in intensity toward lower binding energies compared to the iron signal for the cleaned SWCNTs (Figure 5c), indicating that the Fe(III) is reduced (as a consequence of the oxidation of the $\mathrm{Cr}$ ), confirming that it is the higher valent $\mathrm{Fe}$ that is the cause of the detrimental Cr oxidation, as opposed to catalyst residue generally.

The presence of $\operatorname{Cr}(0)$ is confirmed in the current study after the removal of a significant portion of the iron catalyst, and the prior report [7] appears to also be consistent with the oxidation of the $\mathrm{Cr}$ by the catalyst residue (4.2 wt \%). Although our study did not confirm " $\mathrm{Cr}(\mathrm{CO})_{\mathrm{n}}$ " complexes of SWCNTs per se, it does suggest that such complexes may indeed be prepared upon the removal of 
sufficient catalyst residue and oxygen bound to the SWCNTs. It is interesting to note that there is a negligible decrease in the Raman spectrum $\mathrm{I}_{\mathrm{D}} / \mathrm{I}_{\mathrm{G}}$ ratio from 0.026 to 0.025 after the reaction with $\mathrm{Cr}(\mathrm{CO})_{6}$, indicating that the degree of conjugation of the SWNTs is not influenced by the addition of Group 6 metals.

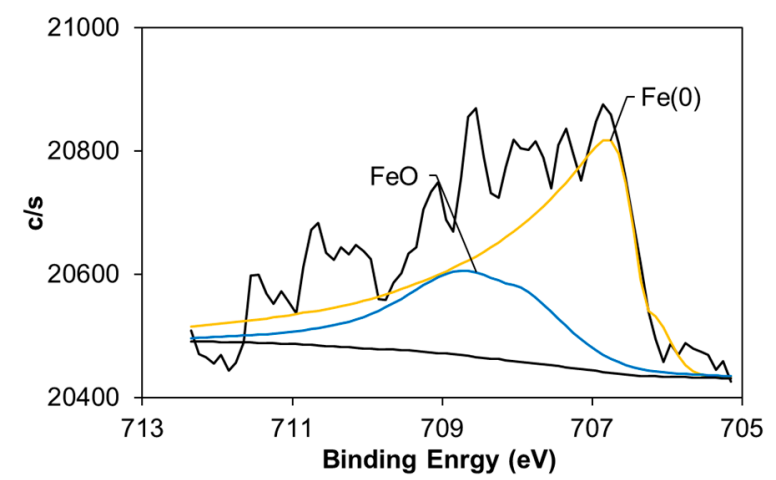

Figure 6. The high resolution Fe $2 \mathrm{p}_{3 / 2}$ XPS signal for the product from the reaction of $\mathrm{Cr}(\mathrm{CO})_{6}$ with microwave/ $\mathrm{HCl} /$ vacuum annealed SWCNTs.

\subsection{Reaction of $\mathrm{Cr}(\mathrm{CO})_{6}$ with Graphene}

In contrast to SWCNTs, graphene can be prepared with high purity $(99.9999 \%)$, and the lack of catalyst residue should preclude the undesired oxidation reaction of the $\mathrm{Cr}(0)$ species. A reaction between graphene and $\mathrm{Cr}(\mathrm{CO})_{6}$ was conducted in THF using a similar procedure to the one previously reported [33]; however, the graphene was annealed under argon $\left(600^{\circ} \mathrm{C}\right)$ before use to remove epoxide functionality [32].

The $\mathrm{Cr} 2 \mathrm{p}_{3 / 2}$ XPS signals of the product from the reaction of $\mathrm{Cr}(\mathrm{CO})_{6}$ with graphene (Figure 7) show the presence of zero-valent chromium before (a) and after (b) sputtering. The concentration of zero-valent chromium decreases from 22.04 to $16.88 \%$ after sputtering ( $1 \mathrm{~min}, 3 \mathrm{kV}, 2 \times 2 \mathrm{~mm}^{2} \mathrm{Ar}^{+}$ beam). However, the total chromium signal (relative to the carbon signal) increases from 4.2 to $9.2 \%$ after sputtering. This increase suggests that chromium prefers to be sandwiched between the graphene sheets in the manner reported by Haddon and co-workers [5]. Interestingly, the XPS spectra are best fitted by the presence of a curve $(575.2 \mathrm{eV})$ that is consistent with the formation of $\mathrm{Cr}$ (graphene $)_{2}$ by analogy with the shift of $\mathrm{Cr}\left(\mathrm{C}_{6} \mathrm{H}_{6}\right)_{2}(575.2 \mathrm{eV})$ [10]. Comparing the curves before and after sputtering, an increase from 17.44 to $22.30 \% \mathrm{Cr}$ (graphene) ${ }_{2}$ is observed. This supports the prior claim that Group 6 metals migrate across SWCNTs to form " $\mathrm{Cr}(\mathrm{SWCNT})_{2}$ ", since such interconnects can only form within bundles, rather than on the surface of the sample [5].

A comparison of the combined percentages of " $\mathrm{Cr}(0)$ " for functionalized graphene (39.5\%) and functionalized SWCNTs $(18.5 \%)$ is consistent with the lower metal catalyst residue in the graphene (ppm). Nevertheless, there is still a significant percentage of the peaks that are consistent with chromium(III) oxide, possibly by atmospheric oxidation post synthesis. Unfortunately, as with the SWCNT complexes, there is a possibility that a curve for (graphene) $\mathrm{Cr}(\mathrm{CO})_{3}$ is overlapping with the $\mathrm{Cr}_{2} \mathrm{O}_{3}$ signal.

Given the presence of $\mathrm{Cr}_{2} \mathrm{O}_{3}$, it is clear that adsorbed oxygen plays an important role in Group 6 metal oxidation on SWCNTs and graphene. As was demonstrated by the study in the previous section, the complete removal of oxygen from the surface of SWCNTs is not accomplished by annealing (Figure 4b). It seems likely that the same is true for graphene, especially considering the fact that graphene and CNTs have been used for gas sensing and adsorption due, in part, to their extremely high surface areas $[26,34,35]$. 

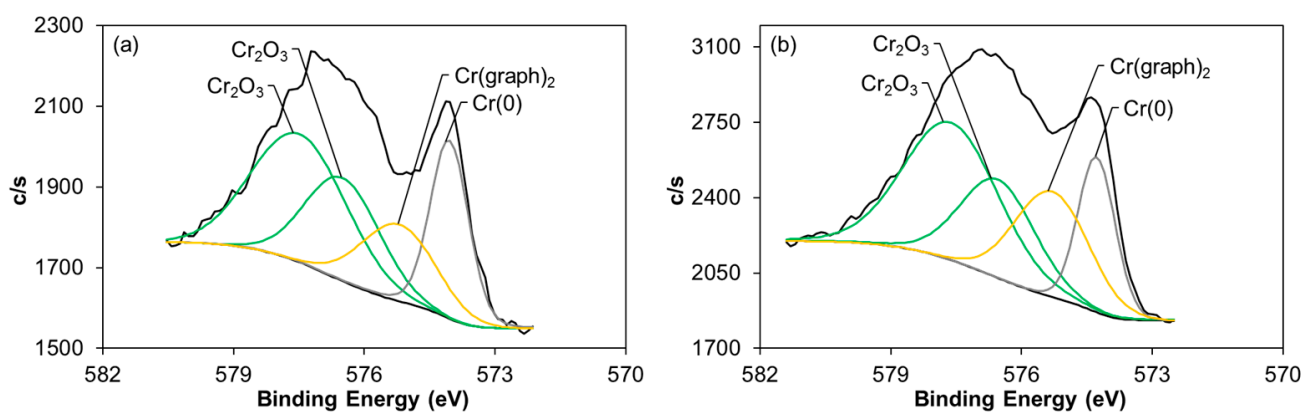

Figure 7. The XPS chromium $2 \mathrm{p}_{3 / 2}$ signals for chromium-functionalized annealed graphene (a) before sputtering and (b) after argon ion sputtering for $1 \mathrm{~min} . \mathrm{Cr}_{2} \mathrm{O}_{3}$ is fit with two curves to account for its complex multiplet splitting [11].

\subsection{Reaction of $W(C O)_{6}$ with Raw and Highly Purified SWCNTs}

The lower propensity for oxidation of $\mathrm{W}(0)$ versus $\mathrm{Cr}(0)$ would suggest that it would be less susceptible to oxidation by the catalyst residue; however, the reaction of either $\mathrm{W}(\mathrm{CO})_{6}$ or $\left(\mathrm{C}_{7} \mathrm{H}_{8}\right) \mathrm{W}(\mathrm{CO})_{3}$ with raw SWCNTs (see Experimental) results in the formation of an oxidized species, as evidenced by XPS analysis. Due to an overlapping fluorine signal resulting from the use of PVDF filter papers (see Experimental), the W 4f XPS peaks could not be used to identify these products. Rather, the less commonly cited $\mathrm{W} 4 \mathrm{~d}_{5 / 2}$ XPS signals were used in this case. The high resolution $\mathrm{W}$ $4 \mathrm{~d}_{5 / 2}$ XPS binding energies of the products from the reaction of raw SWCNTs with both compounds (Table 4) appear to be more similar to that of $\mathrm{WO}_{3}$ rather than $\mathrm{W}(0)$ (Table 5) [36,37]. This is consistent with the oxidation of any adsorbed species. It is worth noting that the reaction with $\left(\mathrm{C}_{7} \mathrm{H}_{8}\right) \mathrm{W}(\mathrm{CO})_{3}$ results in a higher $\mathrm{W}$ content $(4.54 \%)$ than the analogous reaction with $\mathrm{W}(\mathrm{CO})_{6}(2.51 \%)$. This is in line with the results for $\mathrm{Cr}(\mathrm{CO})_{6}$ or $\left(\mathrm{C}_{7} \mathrm{H}_{8}\right) \mathrm{Cr}(\mathrm{CO})_{3}$, see above.

Table 4. Observed XPS W 4d $\mathrm{d}_{5 / 2}$ binding energies and atomic percentages for reactions of SWCNTs.

\begin{tabular}{cccc}
\hline Reagent & W Content (\%) & W 2p3/2 Binding Energy (eV) & FWHM (eV) \\
\hline $\mathrm{W}(\mathrm{CO})_{6}{ }^{\mathrm{a}}$ & 1.01 & 247.8 & 4.07 \\
$\mathrm{~W}(\mathrm{CO})_{6}{ }^{\mathrm{b}}$ & 2.51 & 247.5 & 4.96 \\
$\left(\mathrm{C}_{7} \mathrm{H}_{8}\right) \mathrm{W}(\mathrm{CO})_{3}$ & 4.54 & 247.7 & 4.09 \\
\hline \multicolumn{4}{c}{}
\end{tabular}

Table 5. Literature values of the XPS W $4 \mathrm{~d}_{5 / 2}$ binding energies for various tungsten species.

\begin{tabular}{ccc}
\hline Species & Binding Energy (eV) & Reference \\
\hline $\mathrm{W}(0)$ (metal) & 244.2 & 36 \\
$\mathrm{~W}(\mathrm{CO})_{6}$ & 247.8 & 38 \\
$\mathrm{WO}_{3}$ & 248 & 37 \\
\hline
\end{tabular}

After the results for $\mathrm{Cr}(\mathrm{CO})_{6}$ with purified SWCNTs, we investigated the analogous reaction with $\mathrm{W}(\mathrm{CO})_{6}$. To eliminate metal oxidation due to residual catalyst materials, SWCNTs with ppb catalyst content (supplied by Lockheed Martin) were employed. In order to enable maximum reaction and optimum orientation for $\mathrm{W}(\mathrm{SWCNT})_{2}$ interactions, the purified SWCNTs were spin-coated from aqueous solution onto silicon wafers, allowing for a suitable surface for the reaction (Figure 8).

After annealing the SWCNT-coated wafers $\left(600{ }^{\circ} \mathrm{C}\right)$ used to remove any oxygen-containing functional groups (see above), a concentrated $(14 \mathrm{mg} / \mathrm{mL})$ solution of $\mathrm{W}(\mathrm{CO})_{6}$ was drop-coated on the wafer and allowed to dry. This was then loaded into a $600{ }^{\circ} \mathrm{C}$ argon-purged tube furnace to decompose the $\mathrm{W}(\mathrm{CO})_{6}[38]$. Upon removal from the furnace, the SWCNT-coated wafer had a gray 
film covering much of its surface and seemingly uncoated regions that appeared purple to the naked eye. Inspection by SEM showed the gray regions to have a densely packed layer of $\mathrm{WO}_{3}$ particles $(330 \mathrm{~nm})$ due to excess reagent, which precluded the analysis of the SWCNTs below. In contrast, SEM of the "purple" region showed a sparser coverage of particles (Figure 9). The presence of the particles was undoubtedly a consequence of the excess of $\mathrm{W}(\mathrm{CO})_{6}$ being deposited on the wafers.

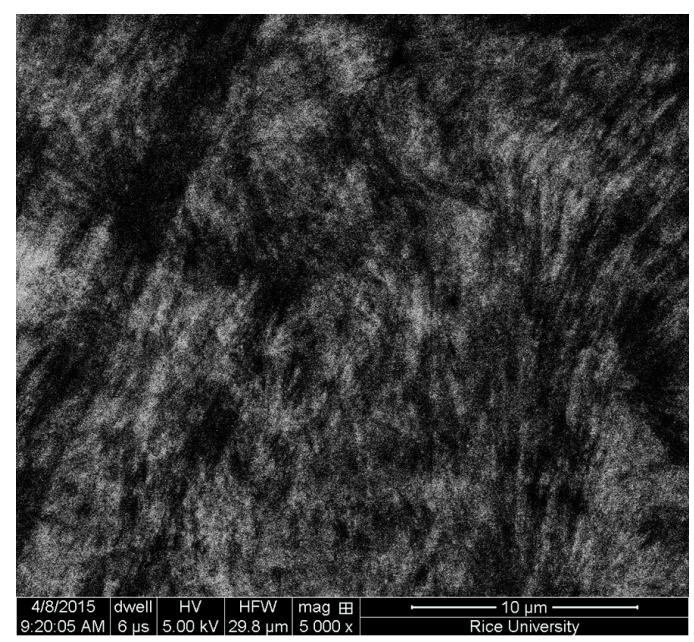

Figure 8. SEM image of high purity SWNTs (ppb Fe) spin-coated on a silicon wafer.

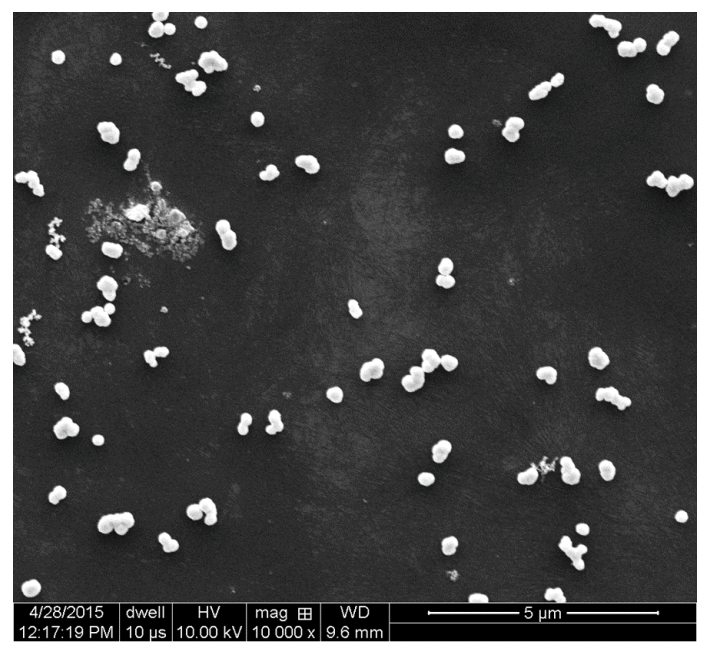

Figure 9. SEM image of the surface of the purple region of the SWNT-coated wafer after reaction with $\mathrm{W}(\mathrm{CO})_{6}$, showing the presence of $\mathrm{W}$ particles with a clear visibility of the SWNTs below.

XPS analysis indicates the presence of significant $\mathrm{W}(1.5 \%)$. The analysis of the high resolution $\mathrm{W}$ $4 \mathrm{f}$ XPS signal shows the presence of both $\mathrm{W}(0)$ and the oxidized product in the form of $\mathrm{WO}_{3}$ in equal concentration (Figure 10a) [37]. The presence of $\mathrm{WO}_{3}$ is expected since these samples were exposed to the air, and is undoubtedly predominantly the particulate features seen on the surface (Figure 9). The XPS depth profile of the sample (Figure 11) indicates an almost constant W intensity with depth, while $C$ shows a small decrease with sputtering. The observed decrease in $C$ and the lack of change in the $\mathrm{W}$ intensity with depth indicates a higher concentration of $\mathrm{W}$ relative to $\mathrm{C}$ with depth. This supports the hypothesis that W has infiltrated the SWCNT layers and bridges the SWCNT-SWCNT junctions, since these junctions are not present at the surface of the sample. The analysis of the high resolution $\mathrm{W} 4 \mathrm{f}$ XPS signal after $15 \mathrm{~s}$ sputtering shows that the concentration of the $\mathrm{W}(0)$ signals increases to $81 \%$ (Figure 10b). Further sputtering and analysis resulted in no change in the spectra for up to $1 \mathrm{~min}$ total sputter time. Thus, the majority of $\mathrm{WO}_{3}$ is on the surface, suggesting that $\mathrm{W}(0)$ 
is present within the SWCNT layers, consistent with its bridging SWCNT-SWCNT junctions [5,7]. Furthermore, this result confirms the proposition that the formation of a significant concentration of $\mathrm{M}(\mathrm{SWCNT})_{2}$ moieties is only possible with ultra low catalyst residue.
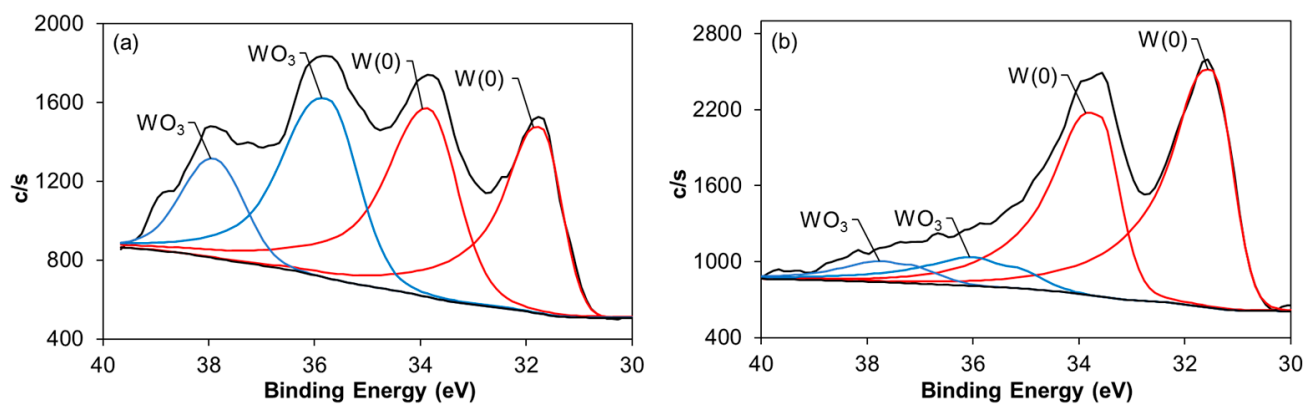

Figure 10. The high resolution XPS W 4f signals for the ultrapure SWNT-coated silica wafer after reaction with $\mathrm{W}(\mathrm{CO})_{6}$ before sputtering (a) and after $15 \mathrm{~s}$ Ar ion sputtering (b).

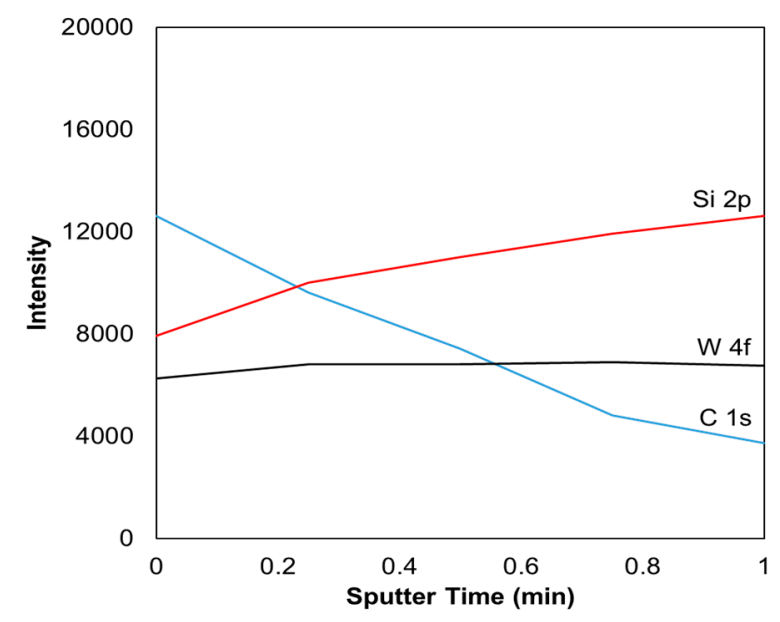

Figure 11. The XPS depth profile of a $\mathrm{W}(\mathrm{CO})_{6}$ functionalized SWNT-coated wafer. The sample was sputtered for $15 \mathrm{~s}$ between data collections. The MultiPak software uses the most intense region of the spectra, along with a correction factor, to calculate the intensity of the elements in the depth profile: $\mathrm{W}=31.6 \mathrm{eV}, \mathrm{Si}=103.3-104.1 \mathrm{eV}$ (varying due to the decrease in $\mathrm{SiO}_{2}$ with depth), and $\mathrm{C}=284.4 \mathrm{eV}$.

\section{Experimental Section}

\subsection{Materials and Characterization}

All reagents were used as received, unless otherwise noted. Pristine HiPco single-walled carbon nanotubes (SWCNTs), 09-HiPco-0093 batch No. 195.7, were obtained from the Carbon Nanotube Laboratory (CNL) at Rice University (Houston, TX, USA) and used as received. High purity annealed SWCNT-coated silicon wafer samples were obtained from Lockheed Martin. The wafer was diced up into 1.0" $\times 0.5^{\prime \prime}$ coupons. Exfoliated graphite, $\left(\mathrm{CH}_{3} \mathrm{CN}\right)_{3} \mathrm{M}(\mathrm{CO})_{3}$, and $\left(\mathrm{C}_{7} \mathrm{H}_{8}\right) \mathrm{M}(\mathrm{CO})_{3}(\mathrm{M}=\mathrm{Cr}, \mathrm{W})$ were prepared according to the methods presented in the literature [39,40]. All solvents were distilled (unless they were obtained from the solvent purification system) and degassed. Glassware was placed in a base bath before use, then washed with soap and water, and dried in an oven overnight. X-ray photoelectron spectra (XPS) were recorded on a PHI Quantera XPS Scanning Microprobe (Physical Electronics, Chanhassen, MN, USA) using a monochromated Al-K $\alpha$ source. All spectra were recorded using a charge neutralizer to limit differential charging and were subsequently calibrated to the carbon peak at a binding energy of $284.5 \mathrm{eV}$. Survey scans were recorded at a pass energy of $140 \mathrm{eV}$ and high-resolution data at a pass energy of $26 \mathrm{eV}$. Before spectral fitting, each spectrum was corrected for 
the reference binding energy for $\mathrm{C} 1 \mathrm{~s}$ to $284.5 \mathrm{eV}$. Data was fitted using MultiPak software (Physical Electronics, Chanhassen, MN, USA). Solution IR spectra were obtained on a PerkinElmer Spectrum Two FT-IR (PerkinElmer, Waltham, MA, USA). Scanning electron microscopic (SEM) images were obtained by a FEI Quanta 400 ESEM FEG high-resolution field emission scanning electron microscope (FEI, Hillsboro, OR, USA). SEM samples were prepared by attaching the SWCNT-coated wafer to an SEM sample stub using carbon tape. Transmission electron microscopy (TEM) images were recorded using a Jeol 1230 High Contrast TEM with a W filament and an operating voltage of $80 \mathrm{kV}$ or on a Jeol 2100 TEM with a field emission electron gun and an operating voltage of $200 \mathrm{kV}$ (Tokyo, Japan). TEM samples were prepared by drop-drying a dilute solution of carbon nanotubes suspended in THF onto a 300-mesh copper grid with a lacey carbon film (Ted Pella, Inc., Redding, CA, USA). Raman spectra were measured in a Renishaw Raman microscope equipped with a $514 \mathrm{~nm}$ excitation laser (Renishaw, West Dundee, IL, USA).

\subsection{Microwave/HCl Treatment of SWCNTs}

Dry HiPco SWCNTs $(0.2 \mathrm{~g})$ were placed in a domestic microwave $(860 \mathrm{~W})$ oven with a beaker $(500 \mathrm{~mL}$ ) half filled with water (for dissipating heat) [27]. The SWCNTs were heated for $1 \mathrm{~min}$ and then allowed to cool. This process was repeated until the SWCNTs had been heated for a total of $10 \mathrm{~min}$. They were then placed in concentrated $\mathrm{HCl}(150 \mathrm{~mL})$, stirred, and refluxed overnight. The mixture was allowed to cool to room temperature and then diluted to $300 \mathrm{~mL}$ with DI water. The SWCNTs were removed by filtering the mixture through a $0.22 \mu \mathrm{m}$ polyvinylidene fluoride (PVDF) filter paper (Millipore, Billerica, MA, USA). They were rinsed with DI water until the $\mathrm{pH}$ of the rinse was no longer acidic. The purified SWCNTs were then placed under vacuum to dry overnight. Once dry, the SWCNTs were put into a quartz boat and loaded into a tube furnace. As the inside of the furnace was preheating to $550{ }^{\circ} \mathrm{C}$, the SWCNTs were degassed under a $600 \mathrm{~mL} / \mathrm{min}$ flow of argon in the tube, just outside of the furnace itself. After $30 \mathrm{~min}$, the SWCNTs were slid into the furnace (using a magnet on the outside of the tube) and heated for $2 \mathrm{~h}$. The SWCNTs were allowed to cool under argon and then quickly transferred to a glove box for storage or a Schlenk flask for immediate use. Yield: $69.6 \%$.

\subsection{Reaction of SWCNTs with $\mathrm{M}(\mathrm{CO})_{6},\left(\mathrm{C}_{7} \mathrm{H}_{8}\right) \mathrm{M}(\mathrm{CO})_{3}$, or $\left(\mathrm{C}_{6} \mathrm{H}_{6}\right) \mathrm{Cr}(\mathrm{CO})_{3}$}

This protocol was adapted from the literature [40]. In a general procedure, SWCNTs $(0.04 \mathrm{~g})$ were placed in a Schlenk flask equipped with a stir bar and were heated at $100{ }^{\circ} \mathrm{C}$ under vacuum overnight. After cooling to $25^{\circ} \mathrm{C}$ under argon, THF $(20 \mathrm{~mL})$ and as appropriate $\mathrm{M}(\mathrm{CO})_{6},\left(\mathrm{C}_{7} \mathrm{H}_{8}\right) \mathrm{M}(\mathrm{CO})_{3}(\mathrm{M}=\mathrm{W}$ or $\mathrm{Cr})$, or $\left(\mathrm{C}_{6} \mathrm{H}_{6}\right) \mathrm{Cr}(\mathrm{CO})_{3}(0.65 \mathrm{mmol})$ were added. The mixture was sonicated in a bath sonicator to disperse the SWCNTs (ca. $2 \mathrm{~min}$ ). The sample was then heated to reflux for four days under an argon stream. The product was allowed to cool and was then centrifuged (4400 rpm for $30 \mathrm{~min}$ ). The supernatant was decanted, leaving a black solid. THF was added and the resulting suspension was sonicated in a bath sonicator to redisperse the product. The dispersion was centrifuged again. This process was repeated three times. The black solid was then dried and stored under vacuum.

\subsection{Reaction of Graphene with $\mathrm{Cr}(\mathrm{CO})_{6}$}

Using a method adapted from the literature [33], graphene $(50 \mathrm{mg})$ and $\mathrm{Cr}(\mathrm{CO})_{6}(0.18 \mathrm{~g}, 0.83 \mathrm{mmol})$ were added to a Schlenk flask in a glove box. THF $(20 \mathrm{~mL})$ was added to the reaction vessel via a cannula and it was then heated to $110{ }^{\circ} \mathrm{C}$ under argon for five days. The suspension was cooled and was then centrifuged at $4400 \mathrm{rpm}$ for $30 \mathrm{~min}$. The yellow supernatant was decanted off, leaving a black solid. THF $(25 \mathrm{~mL})$ was added and the vial was sonicated in a bath sonicator to redisperse the product. The dispersion was centrifuged again. This process was repeated three times. The black solid was then dried and stored under vacuum. 


\subsection{Reaction of Annealed SWCNT-Coated Si Wafer with W(CO) 6}

A coupon of the SWCNT-coated Si wafer was placed in a quartz boat with a magnet attached to it by way of a long steel wire. Using another magnet on the outside of the quartz tube of the furnace, the boat was slid into the end of the tube. The tube was degassed with argon for $30 \mathrm{~min}$ as the furnace was preheated to $600{ }^{\circ} \mathrm{C}$. The boat was then slid into the furnace using the outer magnet and heated under a $600 \mathrm{~mL} / \mathrm{min}$ flow of argon for one hour. The SWCNT-coated Si wafer was slid back to the end of the tube and allowed to cool under argon. The wafer was removed from the tube furnace and placed under flowing argon. A W(CO) 6 solution (ca. $14 \mathrm{mg}, \mathrm{M}=\mathrm{Cr}$ or $\mathrm{W}$ ) in THF $(1 \mathrm{~mL})$ was drop-coated on the wafer's surface and allowed to dry. The wafer was transferred in air to the tube furnace, where it was allowed to sit under $600 \mathrm{~mL} / \mathrm{min}$ flowing argon for about 1 minute (longer purge times resulted in significant loss of $\mathrm{W}(\mathrm{CO})_{6}$ due to sublimation). The argon flow rate was decreased to $100 \mathrm{~mL} / \mathrm{min}$ and the wafer was slid into the $600^{\circ} \mathrm{C}$ furnace. After $20 \mathrm{~min}$, the wafer was slid back out of the furnace and allowed to cool at the end of the quartz tube. The sample was stored under vacuum until it was ready to be analyzed.

\section{Conclusions}

We have shown that the functionalization of carbon materials with Group 6 metals is very challenging and not as straightforward as previously reported [5,7]. Furthermore, the spectroscopic characterization reported was inconsistent with the species claimed. The primarily product is the formation of Group 6 metal oxides as a consequence of the residual SWCNT growth catalyst and oxygen functional groups. Cleaning the SWCNTs using a microwave and $\mathrm{HCl}$ treatment helped to decrease the residual iron catalyst, but, again, it did not eliminate it. However, it enabled the observation of a $\mathrm{Cr}(0)$ species on a SWCNT, albeit contaminated with oxide. Reactions with ultrapure SWCNTs (ppb Fe) and graphene do facilitate the formation of $\mathrm{M}(0)$ species intercalated into the carbon nanomaterial. In the case of graphene, we were able to observe XPS spectra consistent with $\mathrm{Cr}$ (graphene) $)_{2}$ species, but were unable to confirm the presence of "(graphene $) \mathrm{Cr}(\mathrm{CO})_{3}$ " species as a result of their overlapping binding energies with chromium(III) oxides.

We can conclude that in order to make the functionalization of carbon materials with Group 6 metals successful, it is imperative that the carbon materials are extremely pure and free of both a catalyst and absorbed oxygen; however, the former appears to be the greater issue and challenge. This result confirms that the formation of a significant concentration of $\mathrm{M}(\mathrm{SWCNT})_{2}$ or $\mathrm{M}$ (graphene $)_{2}$ moieties is only possible for samples with ultra low catalyst residue; however, the benefit for increased conductivity is clear [40-42] and therefore should prompt future research into new approaches to high purity carbon nanomaterials.

Acknowledgments: This work was supported by the Office of Naval Research (N00014-15-2717), the Welsh Government Sêr Cymru National Research Network in Advanced Engineering and Materials (NRN-150), the Robert A. Welch Foundation (C-0002), and Lockheed Martin Corporation.

Author Contributions: Kourtney D. Wright performed the experiments. Both authors created the Figures and contributed to the manuscript.

Conflicts of Interest: The authors declare no conflict of interest.

\section{References}

1. Pandey, R.; Rao, B.K.; Jena, P.; Blanco, M.A. Electronic structure and properties of transition metal-benzene complexes. J. Am. Chem. Soc. 2001, 123, 3799-3808. [CrossRef] [PubMed]

2. Ruoff, R.S.; Tse, D.S.; Malhotra, R.; Lorents, D.C. Solubility of fullerene $\left(\mathrm{C}_{60}\right)$ in a variety of solvents. J. Phys. Chem. 1993, 97, 3379-3383. [CrossRef]

3. Niyogi, S.; Bekyarova, E.; Hong, J.; Khizroev, S.; Berger, C.; de Heer, W.; Haddon, R.C. Covalent chemistry for graphene electronics. J. Phys. Chem. Lett. 2011, 2, 2487-2498. [CrossRef] 
4. Dag, S.; Gulseren, O.; Ciraci, S. Electronic structure of the contact between carbon nanotube and metal electrodes. Appl. Phys. Lett. 2003, 83, 3180. [CrossRef]

5. Wang, F.; Itkis, M.E.; Bekyarova, E.; Sarkar, S.; Tian, X.; Haddon, R.C. Solid-state bis-hexahapto-metal complexation of single-walled carbon nanotubes. J. Phys. Org. Chem. 2012, 25, 607-610. [CrossRef]

6. Basolo, F. Early kinetic studies on CO substitution reactions of metal carbonyls. J. Organomet. Chem. 1990, 383, 579-586. [CrossRef]

7. Kalinina, I.; Bekyarova, E.; Sarkar, S.; Wang, F.; Itkis, M.E.; Tian, X.; Niyogi, S.; Jha, N.; Haddon, R.C. Hexahapto-metal complexes of single-walled carbon nanotubes. Macromol. Chem. Phys. 2012, 213, 1001-1019. [CrossRef]

8. Hjortstam, O.; Isberg, P.; Soderholm, S.; Dai, H. Can we achieve ultra-low resistivity in carbon nanotube-based metal composites? Appl. Phys. A 2004, 78, 1175-1179. [CrossRef]

9. Subramaniam, C.; Yamada, T.; Kobashi, K.; Sekiguchi, A.; Futaba, D.N.; Yumura, M.; Hata, K. One hundred fold increase in current carrying capacity in a carbon nanotube-copper composite. Nat. Commun. 2013, 4, 2202. [CrossRef] [PubMed]

10. Pignataro, S.; Foffani, A.; Distefano, G. Esca study of some chromium complexes: Ionization energies and multi-peak structure of the spectra. Chem. Phys. Lett. 1973, 20, 350-355. [CrossRef]

11. Biesinger, M.C.; Payne, B.P.; Grosvenor, A.P.; Lau, L.W.M.; Gerson, A.R.; Smart, R.S.C. Resolving surface chemical states in XPS analysis of first row transition metals, oxides and hydroxides: $\mathrm{Cr}, \mathrm{Mn}, \mathrm{Fe}, \mathrm{Co}$ and $\mathrm{Ni}$. Appl. Surf. Sci. 2011, 257, 2717-2730. [CrossRef]

12. Davidson, G.; Riley, E.M. Vibrational spectra of arenechromiumtricarbonyl complexes in solution. Spectrochim. Acta A 1971, 27, 1649-1658. [CrossRef]

13. Myllyoja, S.; Pakkanen, T.A. Deposition of chromium hexacarbonyl on alumina in a fluidized bed reactor. J. Mol. Catal. A Chem. 1998, 136, 153-160. [CrossRef]

14. Cook, J.C.; McCash, E.M. Physisorption of metal carbonyls on Cu(100). Surf. Sci. 1996, 364, L605-L611. [CrossRef]

15. Ziegler, K.J.; Gu, Z.; Peng, H.; Flor, E.L.; Hauge, R.H.; Smalley, R.E. Controlled oxidative cutting of single-walled carbon nanotubes. J. Am. Chem. Soc. 2005, 127, 1541-1547. [CrossRef] [PubMed]

16. Ogrin, D.; Chattopadhyay, J.; Sadana, A.K.; Billups, W.E.; Barron, A.R. Epoxidation and deoxygenation of single-walled carbon nanotubes: Quantification of epoxide defects. J. Am. Chem. Soc. 2006, 128, 11322-11323. [CrossRef] [PubMed]

17. Li, X.; Niu, J.; Zhang, J.; Li, H.; Liu, Z. Labeling the defects of single-walled carbon nanotubes using titanium dioxide nanoparticles. J. Phys. Chem. B 2003, 107, 2453-2458. [CrossRef]

18. Kim, K.T.; Cha, S.I.; Gemming, T.; Eckert, J.; Hong, S.H. The role of interfacial oxygen atoms in the enhanced mechanical properties of carbon-nanotube-reinforced metal matrix nanocomposites. Small 2008, 4, 1936-1940. [CrossRef] [PubMed]

19. Chiang, I.W.; Brinson, B.E.; Huang, A.Y.; Willis, P.A.; Bronikowski, M.J.; Margrave, J.L.; Smalley, R.E.; Hauge, R.H. Purification and characterization of single-wall carbon nanotubes (SWNTs) obtained from the gas-phase decomposition of CO (HiPco process). J. Phys. Chem. B 2001, 105, 8297-8301. [CrossRef]

20. Kayat, J.; Gajbhiye, V.; Tekade, R.K.; Jain, N.K. Pulmonary toxicity of carbon nanotubes: A systematic report. Nanomed. Nanotech. Biol. Med. 2011, 7, 40-49. [CrossRef] [PubMed]

21. Kagan, V.E.; Tyurina, Y.Y.; Tyurin, V.A.; Konduru, N.V.; Potapovich, A.I.; Osipo, A.N.; Kisin, E.R.; Schwegler-Berry, D.; Mercer, R.; Castranova, V.; et al. Direct and indirect effects of single walled carbon nanotubes on RAW 264.7 macrophages: Role of iron. Toxicol. Lett. 2006, 165, 88-100. [CrossRef] [PubMed]

22. Allen, G.; Tucker, P. Multiplet splitting of X-ray photoelectron lines of chromium complexes. The effect of covalency on the $2 p$ core level spin-orbit separation. Inorg. Chim. Acta 1976, 16, 41-45. [CrossRef]

23. Gupta, R.P.; Sen, S.K. Calculation of multiplet structure of core p-vacancy levels. II. Phys. Rev. B 1975, $12,15$. [CrossRef]

24. Unveren, E.; Kemnitz, E.; Hutton, S.; Lippitz, A.; Unger, W.E.S. Analysis of highly resolved X-ray photoelectron $\mathrm{Cr} 2 \mathrm{p}$ spectra obtained with a $\mathrm{Cr}_{2} \mathrm{O}_{3}$ powder sample prepared with adhesive tape. Surf. Interface Anal. 2004, 36, 92-95. [CrossRef]

25. Slater, J.C. Atomic shielding constants. Phys. Rev. 1930, 36, 57. [CrossRef]

26. Giannozzi, P.; Car, R.; Scoles, G. Oxygen adsorption on graphite and nanotubes. J. Chem. Phys. 2003, 118, 1003. [CrossRef] 
27. Gomez, V.; Irusta, S.; Lawal, O.B.; Adams, W.; Hauge, R.H.; Dunnill, C.W.; Barron, A.R. Enhanced purification of carbon nanotubes by microwave and chlorine cleaning procedures. RSC Adv. 2016, 6, 11895-11902. [CrossRef]

28. Cotton, F.A.; Wilkinson, G. Advanced Inorganic Chemistry, 5th ed.; Wiley: New York, NY, USA, 1988.

29. Jung, A.; Graupner, R.; Ley, L.; Hirsch, A. Quantitative determination of oxidative defects on single walled carbon nanotubes. Phys. Stat. Sol. B 2006, 243, 3217-3220. [CrossRef]

30. McIntyre, N.S.; Zetaruk, D.G. X-ray photoelectron spectroscopic studies of iron oxides. Anal. Chem. 1977, 49, 1521-1529. [CrossRef]

31. Edwards, E.R.; Antunes, E.F.; Botelho, E.C.; Baldan, M.R.; Corat, E.J. Evaluation of residual iron in carbon nanotubes purified by acid treatments. Appl. Surf. Sci. 2011, 258, 641-648. [CrossRef]

32. Chattopadhyay, J.; Mukherjee, A.; Hamilton, C.E.; Kang, J.H.; Chakraborty, S.; Guo, W.; Kelly, K.F.; Barron, A.R.; Billups, W.E. Graphite epoxide. J. Am. Chem. Soc. 2008, 130, 5414-5415. [CrossRef] [PubMed]

33. Sarkar, S.; Niyogi, S.; Bekyarova, E.; Haddon, R.C. Organometallic chemistry of extended periodic $\pi$-electron systems: Hexahapto-chromium complexes of graphene and single-walled carbon nanotubes. Chem. Sci. 2011, 2, 1326-1333. [CrossRef]

34. Schedin, F.; Geim, A.K.; Morozov, S.V.; Hill, E.W.; Blake, P.; Katsnelson, M.I.; Novoselov, K.S. Detection of individual gas molecules adsorbed on graphene. Nat. Mater. 2007, 6, 652-655. [CrossRef] [PubMed]

35. Stan, G.; Bojan, M.J.; Curtarolo, S.; Gatica, S.M.; Cole, M.W. Uptake of gases in bundles of carbon nanotubes. Phys. Rev. B 2000, 62, 2173. [CrossRef]

36. Sarma, D.D.; Rao, C.N.R. XPES studies of oxides of second- and third-row transition metals including rare earths. J. Electron. Spectrosc. Relat. Phenom. 1980, 20, 25-45. [CrossRef]

37. McGuire, G.E.; Schweitzer, G.K.; Carlson, T.A. Core electron binding energies in some Group IIIA, VB, and VIB compounds. Inorg. Chem. 1973, 12, 2450-2453. [CrossRef]

38. Sahoo, P.K.; Kamal, S.S.K.; Premkumar, M.; Kumar, T.J.; Sreedhar, B.; Singh, A.K.; Srivastava, S.K.; Sekhar, K.C. Synthesis of tungsten nanoparticles by solvothermal decomposition of tungsten hexacarbonyl. Int. J. Refract. Met. H 2009, 27, 784-791. [CrossRef]

39. Kubas, G.J. Preparation and use of $\mathrm{W}(\mathrm{CO})_{3}(\mathrm{NCR})_{3}(\mathrm{R}=\mathrm{Et}, \mathrm{Pr})$ as improved starting materials for syntheses of tricarbonyl $\left(\eta^{6}\right.$-cycloheptatriene)tungsten and other substituted carbonyl complexes. Inorg. Chem. 1983, 22, 692-694. [CrossRef]

40. Sarkar, S.; Zhang, H.; Huang, J.-W.; Wang, F.; Bekyarova, E.; Lau, C.N.; Haddon, R.C. Organometallic hexahapto functionalization of single layer graphene as a route to high mobility graphene devices. Adv. Mater. 2013, 25, 1131-1136. [CrossRef] [PubMed]

41. Ketolainen, T.; Havu, V.; Puska, M.J. Enhancing conductivity of metallic carbon nanotube networks by transition metal adsorption. J. Chem. Phys. 2015, 142, 054705. [CrossRef] [PubMed]

42. Pekker, A.; Chen, M.; Bekyarova, E.; Haddon, R.C. Photochemical generation of bis-hexahapto chromium interconnects between the graphene surfaces of single-walled carbon nanotubes. Mater. Horiz. 2015, 2, 81-85. [CrossRef]

(C) 2017 by the authors. Licensee MDPI, Basel, Switzerland. This article is an open access article distributed under the terms and conditions of the Creative Commons Attribution (CC BY) license (http://creativecommons.org/licenses/by/4.0/). 